Volume: 2, Issue: 1, January-March 2017, Pages: 126, DOI: http://dx.doi.org/10.19082/ah126

\title{
METHODS OF USING SNOMED CT IN ELECTRONIC HEALTH RECORDS
}

\author{
Khadijeh moulaei ${ }^{1}$. maryam ahmadi ${ }^{2 *}$
}

1: MSc Student of Medical Informatics in University of Medical Sciences;

2: Professor of Health Information Management, Department of Health Information Management, School of Health Management and Information Sciences, Iran University of Medical Sciences, Tehran, Iran

Correspondence:

E-mail: Ahmadi.m@iums.ac.ir.

\section{TYPE OF ARTICLE: CONFERENCE ABSTRACT}

\author{
ABSTRACT \\ Introduction: Nowadays, there are many improvements in the field of health care, especially electronic records. \\ One of these improvements is the use of the most comprehensive multilingual SNOMED CT terminology in \\ health care electronic health records. \\ Methods: The present study is a review article, which was created with the aim of examining different ways of \\ using SNOMED CT in electronic health records. \\ Results: The world uses various terminologies to implement electronic health records, but the SNOMED CT \\ terminology is one of the most comprehensive in this field. Its applications in various fields, including storing, \\ retrieving, and integrating data and information has caused an increase in the quality and safety of health care. \\ Conclusion: This study examined different ways to use SNOMED CT in electronic health records. \\ Electronic records using SNOMED CT will have better performance and enhance the quality and safety \\ of health care. \\ KEYWORDS: Electronic health records, (EHR), SNOMED CT, Application, Health care
}

\footnotetext{
Abstracts of First National Congress of Medical Informatics, Mashhad, Iran, February 2017

(C) 2017 The Authors. This is an open access article under the terms of the Creative Commons Attribution-NonCommercialNoDerivs License, which permits use and distribution in any medium, provided the original work is properly cited, the use is non-commercial and no modifications or adaptations are made.
} 